\section{International}

\section{Journal of Animal}

\section{Science}

\author{
Article Information \\ Received date: Jul 27, 2017 \\ Accepted date: Jul 31, 2017 \\ Published date: Aug 02, 2017
}

*Corresponding author

Yun-Feng Zhang, Department of Neuroscience, University of Pennsylvania, Perelman School of Medicine, USA;

Tel: (215) 746-2791; Fax: 215-573-9050; Email(s): zhangyunfeng1983@163.com, zhang18@mail.med.upenn.edu

Distributed under Creative Commons CC-BY 4.0

\title{
Taking Gender Difference Seriously in Mouse Models of Depression
}

\author{
Chanyi Lu ${ }^{1,2,5 *}$, Yao-Yao $\mathrm{Li}^{1,2 *}$, Hua-Zhen $\operatorname{Lin}^{3,4 *}$ and Yun-Feng Zhang ${ }^{1,2,6 *}$ \\ ${ }^{1}$ Department of Ophthalmology \& Optometry, Wenzhou Medical University, China \\ ${ }^{2}$ Ministry of Health P. R. China and Zhejiang Provincial Key Laboratory of Ophthalmology and Optometry, \\ P. R. China \\ ${ }^{3}$ Yuying Children's Hospital, Wenzhou Medical University, China \\ ${ }^{4}$ Department of Medicine, Wenzhou Medical University, China \\ ${ }^{5}$ University of Pennsylvania School of Dental Medicine, USA \\ ${ }^{6}$ Department of Neuroscience, University of Pennsylvania Perelman School of Medicine, USA \\ ${ }^{*}$ Authors contributed equally
}

\section{Introduction}

Depression as one of the most prevalent and life-threatening forms of mental illness affects more than $1 / 5$ of the world's population [1]. A great number of mouse models emerging aim to decipher the mechanism underlying depression [1,2]. For rodent models with depressive-like behaviors, some researchers preferred male animals to female ones [3-7] while the others used both male and female animals during their studies [2,8-10], which makes it controversial in recruitment of animals when performing depression-related studies. The possible disadvantage of the former studies only focusing on male animals is the omission of some potentially important and interesting phenomena that exhibited only by female animals, and the likely flaw of the latter studies may be the double of samples size resulting from the involvement of both male and female subjects during the experiment.

Several lines of evidence have confirmed the sexual dimorphic variances in depression-like behaviors/depression in both animal models [9-12] and human beings [13-17]. Our previous work indicated that mouse model with depression-like behaviors induced by light deprivation showed sex difference in both neural excitability and behaviors [9]. The female mice exhibited decreased neural excitability of motor cortical layer 5 pyramidal neurons (L5PCs) and lower active behaviors in the forced swimming test and tail suspension test, suggesting a possible causal relationship between the decreased excitability of L5PCs and the lower activities in female mice with depression-like behaviors. Moreover, a recent study demonstrated that female rats were susceptible to depressivelike phenotypes when facing acute and repeated stress relative to males [10]. In human beings, women are much easier to suffer from depression than men [18] and sex differences also exist in antidepressant treatment responses $[13,17]$. Recently, one new epidemiological research on adolescents showed sex differences in depression incidence by age, and the incidence proportion was higher in female subjects than in males at all ages tested [19]. All these evidence highlights the popularity of sex differences in depression-like behaviors/depression in both animal models and humans. Also, it underscores the necessity and importance of taking both male and female subjects into consideration when performing studies pertaining to depression.

The advantage of sex-based considerations during the experimental design and research concerning depression is that researchers could explore interactions between 'sex' and other independent variables, for example, the temperature and light intensity. Balancing sex in animal studies related to depression could reduce the bias and improve the accuracy of the conclusion, which, in the end, will provide much more valuable information to clinical studies. Nowadays, the new policy of National Institutes of Health (NIH) of United States of America has considered the sex as a biological variable factor, and encourages scientific researchers to perform studies involving both male and female vertebrate animals and humans [20], which will certainly empower our understanding of depression and other diseases in both men and women. Collectively, consideration of gender differences in studying depression should be taken more seriously and carefully, and unraveling the underpinnings of sex differences in depression/depression-like behaviors will definitely shed light on mechanisms of depression and optimize therapeutic approaches in both sexes.

\section{Acknowledgements}

This study was supported by the grants from the Wenzhou Science and Technology Plans (No.Y20140139), the Foundation of School of Ophthalmology \& Optometry, The Eye Hospital, 
Wenzhou Medical University (YNCX201311), the Natural Science Foundation of Zhejiang Province of China (No. LQ14H120003) and the National Natural Science Foundation for Young Scientists of China (No. 81301117).

\section{References}

1. Stepanichev M, Dygalo NN, Grigoryan G, Shishkina GT, Gulyaeva N. Roden models of depression: neurotrophic and neuroinflammatory biomarkers. Biomed Res Int. 2014; 932757.

2. Zhang Y-F, Li Q-Q, Qu J, Sun C-M,Wang Y. Alterations of motor cortical microcircuit in a depressive-like mouse model produced by light deprivation. Neuroscience. 2017; 341: 79-94.

3. Chaudhury D, Walsh JJ, Friedman AK, Juarez B, Ku SM, Koo JW, et al. Rapid regulation of depression-related behaviours by control of midbrain dopamine neurons. Nature. 2013; 493: 532-536.

4. Kim KS, Han PL. Optimization of chronic stress paradigms using anxiety- and depression-like behavioral parameters. J Neurosci Res. 2006; 83: 497-507.

5. Seo JS, Zhong $P$, Liu A, Yan Z,Greengard P. Elevation of $p 11$ in lateral habenula mediates depression-like behavior. Mol Psychiatry. 2017.

6. Filho CB, Jesse CR, Donato F, Del Fabbro L, Gomes de Gomes M, Rossito Goes AT, et al. Chrysin promotes attenuation of depressive-like behavior and hippocampal dysfunction resulting from olfactory bulbectomy in mice. Chem Biol Interact. 2016; 260: 154-162.

7. Fuchikami M, Thomas A, Liu R, Wohleb ES, Land BB, DiLeone RJ, et al. Optogenetic stimulation of infralimbic PFC reproduces ketamine's rapid and sustained antidepressant actions. Proc Natl Acad Sci U S A. 2015; 112: 81068111.

8. Ramirez S, Liu X, MacDonald CJ, Moffa A, Zhou J, Redondo RL, et al Activating positive memory engrams suppresses depression-like behaviour. Nature. 2015; 522: 335-339.

9. Lu C, Wang Y, Zhang YF. Light deprivation produces a sexual dimorphic effect on neural excitability and depression-like behavior in mice. Neurosci Lett. 2016; 633: 69-76.
10. Rincon-Cortes M, Grace AA. Sex-dependent effects of stress on immobility behavior and VTA dopamine neuron activity: modulation by ketamine. Int J Neuropsychopharmacol. 2017.

11. Mourlon V, Baudin A, Blanc O, Lauber A, Giros B, Naudon L, et al. Maternal deprivation induces depressive-like behaviours only in female rats. Behav Brain Res. 2010; 213: 278-287.

12. Drossopoulou G, Antoniou K, Kitraki E, Papathanasiou G, Papalexi E, Dalla $C$, et al. Sex differences in behavioral, neurochemical and neuroendocrine effects induced by the forced swim test in rats. Neuroscience. 2004; 126 : 849-857.

13. Gorman JM. Gender differences in depression and response to psychotropic medication. Gend Med. 2006; 3: 93-109.

14. Thiels C, Linden M, Grieger F,Leonard J. Gender differences in routine treatment of depressed outpatients with the selective serotonin reuptake inhibitor sertraline. Int Clin Psychopharmacol. 2005; 20: 1-7.

15. Kessler RC, Barker PR, Colpe LJ, Epstein JF, Gfroerer JC, Hiripi E, et al. Screening for serious mental illness in the general population. Arch Gen Psychiatry. 2003; 60: 184-189.

16. Kornstein SG, Schatzberg AF, Thase ME, Yonkers KA, McCullough JP Keitner $\mathrm{Gl}$, et al. Gender differences in chronic major and double depression. J Affect Disord. 2000; 60: 1-11.

17. Sloan DM, Kornstein SG. Gender differences in depression and response to antidepressant treatment. Psychiatr Clin North Am. 2003; 26: 581-594.

18. Hales RE, Yudofsky SC,Talbott JA. Textbook of Psychiatry. 3rd ed Washington DC: American Psychiatric Press. 1999.

19. Breslau J, Gilman SE, Stein BD, Ruder T, Gmelin T, Miller E. Sex differences in recent first-onset depression in an epidemiological sample of adolescents. Transl Psychiatry. 2017; 7: 1139.

20. Clayton JA,Collins FS. Policy: NIH to balance sex in cell and animal studies Nature. 2014; 509: 282-283. 